\title{
Elevation and characteristics of Rab30 and S100a8/S100a9 expression in an early phase of liver regeneration in the mouse
}

\author{
MITSURU CHIBA $^{1,2}$, SOICHIRO MURATA ${ }^{1}$, ANDRIY MYRONOVYCH ${ }^{1}, \mathrm{KEISUKE} \mathrm{KOHNO}^{1}$, \\ NORIKO HIRAIWA $^{3}$, MASAHIDE NISHIBORI ${ }^{4}$, HIROSHI YASUE ${ }^{2}$ and NOBUHIRO OHKOHCHI ${ }^{1}$ \\ ${ }^{1}$ Department of Surgery, Graduate School of Comprehensive Human Sciences, University of Tsukuba, 1-1-1 Tennoudai, \\ Tsukuba, Ibaraki 305-8575; ${ }^{2}$ Animal Genome Research Unit, National Institute of Agrobiological Sciences, \\ 2 Ikenodai, Tsukuba, Ibaraki 305-0901; ${ }^{3}$ BioResource Center, RIKEN, 3-1-1 Koyadai, Tsukuba, \\ Ibaraki 305-0074; ${ }^{4}$ Graduate School of Biosphere Science, Hiroshima University, \\ 1-4-4 Kagamiyama, Higashihiroshima, Hiroshima 739-8528, Japan
}

Received November 23, 2010; Accepted January 19, 2011

DOI: 10.3892/ijmm.2011.614

\begin{abstract}
Recent studies have revealed that cytokines, including $\mathrm{TNF} \alpha$ and IL-6 play key roles in the priming phase of liver regeneration. However, further knowledge of molecular events in the priming phase is needed for more comprehensively understanding the initiation of liver regeneration. In the present study, we attempted to identify additional genes involved in an early phase (2-6 h post partial hepatectomy, $\mathrm{PH})$. The expression of 71 genes was shown to be up-regulated more than 3 -fold in the liver at $2 \mathrm{~h}$ and $6 \mathrm{~h}$ post $\mathrm{PH}$, as compared to $0 \mathrm{~h}$ (normal livers) using microarray analysis. Among them, Rab30 and S100a8/S100a9, were identified as novel genes up-regulated over 20 -fold at $2 \mathrm{~h}$ post $\mathrm{PH}$ as compared to normal liver, and were further examined by RT-qPCR to confirm microarray results. Rab30 showed no significant up-regulation in organs other than the liver, whereas S100a8/S100a9 showed significant up-regulation in other organs, such as the lung and spleen at $6 \mathrm{~h}$ post $\mathrm{PH}$ as compared to those of sham-operated mice, indicating the existence of a different up-regulation machinery between Rab30 and S100a8/ S100a9. Their expression was further investigated in the liver at various developmental stages. Rab30 was shown to be expressed only in newborn liver, whereas S100a8/S100a9 was highly expressed in embryo stages, and exhibited the highest levels in newborn liver. These findings imply that Rab30 and S100a8/S100a9 are possibly involved in the functional switch from hematopoiesis support to metabolism in the newborn stage, but might play different roles in liver development. In conclusion, Rab30 and S100a8/S100a9 were indicated to play
\end{abstract}

Correspondence to: Dr Hiroshi Yasue, Animal Genome Research Unit, National Institute of Agrobiological Sciences, 2 Ikenodai, Tsukuba, Ibaraki 305-0901, Japan

E-mail: hyasue@affrc.go.jp

Key words: partial hepatectomy, development, S100a8/S100a9, Rab30 roles in the initiation of liver regeneration as well as possibly in the functional switch of the liver in the newborn stage.

\section{Introduction}

The liver is an important organ that plays a central role in the metabolic homeostasis of the body, which consists of metabolism, synthesis, storage and redistribution of carbohydrates, fat and vitamins. In addition, the liver produces a large number of proteins, including serum albumin, enzymes, and cofactors (1). From the developmental point of view, the liver supports hematopoiesis at the embryonic stages, and undergoes functional switches to gain major functions in metabolic homeostasis at the postnatal stages (2). Most of these functions at the postnatal stages are carried out by the hepatocytes, a parenchymal cell type that comprises about $80 \%$ of the hepatic cells. The remaining $20 \%$ of the hepatic cells are non-parenchymal cells including Kupffer, stellate, endothelial cells, and lymphocytes. These cells have various functions such as phagocytosis and cytokine production (1).

The occurrence of liver regeneration has been clearly demonstrated by Higgins et al (3) in rodents that underwent removal of two-thirds of this organ (partial hepatectomy, $\mathrm{PH})$. Rodents that underwent $\mathrm{PH}$ regained the original mass of the liver by enlargement of the remaining liver one week post $\mathrm{PH}(1,3)$. This regeneration of the liver has been found not to be a genuine regeneration, such as that observed in amphibians; however, it provides the basis for clinical liver treatment, such as surgery to eliminate hepatic cancer and for performing transplantation. The mechanisms of liver regeneration have been the focus of many investigations over the years. Recently, cytokines including IL-6 and TNF $\alpha$ have been demonstrated to be involved in the initiation of the liver regeneration (1). However, the study on Il6 knock-out mice has shown that IL-6 is not indispensable in liver regeneration (4). Likewise, the analysis of Tnf $\alpha$ knock-out mice has shown that $T N F \alpha$ is not indispensable in liver regeneration (5). Hence, currently, the overlapping multiple pathways related to the cytokines are considered to be involved in the initiation 
of liver regeneration post $\mathrm{PH}$ (6-8). In addition, peptides/ proteins released from organs other than the liver were shown to participate in liver regeneration. For example, insulin from the pancreas, epidermal growth factor from the duodenum and salivary glands, norepinephrine from the adrenal glands, and triiodothyronine (T3) from the thyroid gland have been demonstrated to be implicated in liver regeneration (7).

Although many factors have been shown to be involved in liver regeneration as mentioned above, further knowledge of the molecular events involved in this process is essential to more comprehensively understand the regeneration. In the present study, we have attempted to identify novel up-regulated genes in the priming and in the extended phase of liver regeneration using microarray and RT-qPCR analyses, and then determine the expression sites of those genes using in situ hybridization in order to further understand their function.

\section{Materials and methods}

Partial hepatectomy. Eight-week-old (8W) SPF (specific pathogen-free) male BALB/c mice weighing 24-28 g were purchased from Clea (Tokyo, Japan). The mice were maintained in a temperature-controlled room on a $12 \mathrm{~h}$ light-dark cycle, with free access to water and standard chow. PH (70\%) was performed on anesthetized mice, essentially following the procedure described by Higgins et al (3). The mice were sacrificed at five time-points: $0,2,6,12$, and $24 \mathrm{~h}$ post $\mathrm{PH}$ ( $n=3$ in each time-point). Sham-operation was performed on mice as a control ( $n=3$ for each time-point).

Tissue samples. For RNA analysis, hepatectomized and shamoperated $8 \mathrm{~W} \mathrm{BALB} / \mathrm{c}$ mice were sacrificed at the time-points indicated above, and the organs/tissues (liver, brain, heart, lung, spleen, kidney, and testis) of the mice were collected, immediately frozen in liquid nitrogen and stored at $-80^{\circ} \mathrm{C}$ until use. Livers at different developmental stages, i.e., embryonic day (E) 14, E17, newborn (NB), one-week-old (1W), and $8 \mathrm{~W}$, were obtained from C57BL/6J mice at the RIKEN BioResource Center (Ibaraki, Japan). The livers were frozen as described above and stored at $-80^{\circ} \mathrm{C}$ until use.

For in situ hybridization, the organs/tissues of postnatal mice, except for NB mice, were first fixed in situ by perfusion of $4 \%$ (w/v in phosphate-buffered saline) ice-cold paraformaldehyde solution into the mice, and then the resulting organs/ tissues were excised to be further fixed overnight in the paraformaldehyde solution. The organs/tissues of NB mice and embryos were excised to be fixed overnight in the paraformaldehyde solution. The organs/tissues thus fixed were embedded in paraffin blocks, and then sliced into $4 \mu \mathrm{m}$ sections to make a tissue array on glass slides.

Animal care and experiments. All animal experiments in this study were carried out according to the Guidelines of the University of Tsukuba for the Care of Laboratory Animals and the Regulation for Animal Experiments or according to the standards established by RIKEN under the Guidelines for the care and use of experimental animals.

Total RNA extraction. Total RNAs were isolated from frozen tissues using Isogen (Nippon Gene, Tokyo, Japan) according to the manufacturer's instruction. The quality and concentration of the RNA were assessed with the NanoDrop Spectrophotometer (NanoDrop Technologies, WI, USA) according to the manufacturer's instructions. The 260/280 nm absorbance ratios of all RNA samples were 1.8-2.0. The Agilent 2100 Bioanalyzer (Agilent Technologies, CA, USA) and the RNA 6000 Nano LabChip kit (Agilent Technologies) were used to evaluate the integrity of the RNA. Total RNAs examined were shown to be evaluated as RNA integrity numbers (RIN) over 8.0. Based on the instructions of the Bioanalyzer, total RNAs thus obtained were judged to be suitable for further analysis; i.e., microarray analysis and RT-qPCR.

Microarray analysis. An equal amount of total RNAs prepared from 3 liver samples at each time-point were mixed to make a total RNA mixed sample of each time-point. Cyanine 3 (Cy3)-CTP-labeled cRNA was synthesized from $400 \mathrm{ng}$ of the $0 \mathrm{~h}$ total RNA mixed sample (total RNA mixed sample of normal livers) using a Low RNA Input Linear Amplification kit (Agilent Technologies); and cyanine 5 (Cy5)-CTP-labeled cRNAs were synthesized from $400 \mathrm{ng}$ of $2,6,12$, and $24 \mathrm{~h}$ total RNA mixed samples following the manufacturer's instructions.

Agilent 44K x 4 mouse oligo microarray slides (Agilent Technologies) were hybridized with a mixture of $\mathrm{Cy} 3$ and Cy5-labeled cRNAs (825 ng each) in a hybridization solution prepared with the in situ Hybridization kit Plus (Agilent Technologies), following the manufacturer's instructions. The Cy3 and Cy5 fluorescence signal images on the slides were obtained by a DNA microarray scanner (Agilent Technologies), and processed using the Feature Extraction software version 8.1, based on the manufacturer's instructions. The signals of the genes thus obtained were subjected to quantile normalization in order to examine the differences of gene expression between the $0 \mathrm{~h}$ RNA and the other RNA mixed samples.

$R T-q P C R$. An aliquot of each RNA sample was mixed with an RNA fragment (218 nucleotides) synthesized from the pEGFP-C1 vector (Invitrogen, CA, USA) to attain a final amount of $5 \times 10^{-5} \mathrm{pmol} / 10 \mu \mathrm{g}$ total RNA (9). The resulting mixtures were subjected to first-strand cDNA synthesis using random hexamer primers (Takara, Shiga, Japan) and Reverse Transcriptase (Promega, Tokyo, Japan), according to the procedure recommended by Promega. The first-strand cDNAs were then subjected to quantitative PCR (qPCR) using SYBRGreen Real-time PCR Master Mix Plus (Toyobo, Osaka, Japan) and the primer pairs described below. The qPCRs were conducted using the Applied Biosystem 7500 Real-Time PCR system (Applied Biosystems, CA, USA) under the conditions of $1 \mathrm{~min}$ at $95^{\circ} \mathrm{C}$ followed by 40 cycles each at $95^{\circ} \mathrm{C}$ for $15 \mathrm{sec}$ and $60^{\circ} \mathrm{C}$ for $60 \mathrm{sec}$, following the procedure recommended by the manufacturer. Results of qPCR are presented as the means \pm standard errors (SE) of the samples.

Since the copy numbers of gene transcripts were shown to be different depending on the region of the genes (10), sequences for the primer pairs of qPCR and probes for in situ hybridization were selected in a region as close as possible to the probe sequences of the microarray using Genetyx software 
Table I. Primer sequences for RT-qPCR.

\begin{tabular}{|c|c|c|c|}
\hline Primer name & Sequence $\left(5^{\prime} \rightarrow 3^{\prime}\right)$ & Size (mer) & PCR products $(b p)$ \\
\hline Igfbpl-forward & ATCTGCCAAACTGCAACAAG & 20 & 121 \\
\hline Igfbpl-reverse & GACCCAGGGATTTTCTTTC & 19 & \\
\hline Ccndl-forward & CTGTTAGGTTCTAGTGTTCCGTC & 23 & 120 \\
\hline Ccndl-reverse & CAGCTTGCTAGGGAACTTGG & 20 & \\
\hline Rab30-forward & GGTTGCGGGAGATAGAACAG & 20 & 121 \\
\hline Rab30-reverse & GCCTCTGAGAACTCTTCTGCT & 21 & \\
\hline S100a9-forward & CACAGTTGGCAACCTTTATGAA & 22 & 69 \\
\hline S100a9-reverse & GGTCCTCCATGATGTCATTTATG & 23 & \\
\hline S100a8-forward & CTGAGTGTCCTCAGTTTGTG & 20 & 78 \\
\hline S100a8-reverse & TTGCATTGTCACTATTGATGTCC & 23 & \\
\hline
\end{tabular}

Table II. cDNA probe sequences for in situ hybridization.

\begin{tabular}{|c|c|c|}
\hline Probe name & Sequence $\left(5^{\prime} \rightarrow 3^{\prime}\right)$ & Size (mer) \\
\hline $\begin{array}{l}\text { Prml antisense } \\
\text { cRNA probe } \\
\text { (positive control) }\end{array}$ & $\begin{array}{l}\text { UUUUCAACAUUUAUUGACAGGUGGCAUUGUUCCUUAGCAGGCUCCUG } \\
\text { UUUUUCAUCGGACGGUGGCAUUUUUCAAGAUGUGGCGAGAUGCUCUU } \\
\text { GAAGUCUGGUAAAAUUCUCACGCAGG }\end{array}$ & 120 \\
\hline $\begin{array}{l}L N E \text { cRNA probe } \\
\text { (negative control) }\end{array}$ & $\begin{array}{l}\text { UGCCUGCAAAGAUGAGGAGGGAUUGCAGCGUGUUUUUAAUGAGGUCA } \\
\text { UCACGGGAUCCCAUGUGCGUGACGGACAUCGGGAAACGCCAAAGGAG } \\
\text { AUUAUGUACCGAGGAAGAAUGUCGCU }\end{array}$ & 120 \\
\hline $\begin{array}{l}\text { Rab30 antisense } \\
\text { cRNA probe }\end{array}$ & $\begin{array}{l}\text { GCCUCUGAGAACUCUUCUGCUCUCUGCUGGGAGACCUCUCGCCUUUCA } \\
\text { GCCAGGUCAAUCUUGUUGCCUACUAACACAGUGAUGACUUUAUUGCU } \\
\text { AGCAUACUGUUCUAUCUCCCGCAACC }\end{array}$ & 121 \\
\hline $\begin{array}{l}\text { S100a9 antisense } \\
\text { cRNA probe }\end{array}$ & $\begin{array}{l}\text { AGCUUCUCAUGACAGGCAAAGAUCAACUUUGCCAUCAGCAUCAUACA } \\
\text { CUCCUCAAAGCUCAGCUGAUUGUCCUGGUUUGUGUCCAGGUCCUCCA } \\
\text { UGAUGUCAUUUAUGAGGGCUUCAUUU }\end{array}$ & 120 \\
\hline
\end{tabular}

Table III. Top 10 genes up-regulated more than 3-fold in the liver at 2 and $6 \mathrm{~h}$ post $\mathrm{PH}$, compared to that at $0 \mathrm{~h}$ post $\mathrm{PH}$.

\begin{tabular}{|c|c|c|c|c|c|c|}
\hline \multirow[t]{2}{*}{ Gene symbol } & \multirow[t]{2}{*}{ Accession no. } & \multicolumn{4}{|c|}{ Expression (fold-change) } & \multirow[t]{2}{*}{ Gene name } \\
\hline & & $2 \mathrm{~h}$ & $6 \mathrm{~h}$ & $12 \mathrm{~h}$ & $24 \mathrm{~h}$ & \\
\hline$M t 2$ & NM_008630 & 101.27 & 130.82 & 106.96 & 50.27 & Metallothionein 2 \\
\hline Igfbpl & NM_008341 & 85.37 & 82.62 & 29.83 & 6.57 & Insulin-like growth factor binding protein 1 \\
\hline S100a9 & NM_009114 & 48.55 & 38.74 & 16.98 & 23.18 & S100 calcium binding protein A9 \\
\hline Saal & NM_009117 & 32.47 & 69.51 & 61.27 & 62.57 & Serum amyloid A1 \\
\hline Saa2 & NM_011314 & 28.08 & 34.78 & 32.42 & 40.24 & Serum amyloid A2 \\
\hline $2310016 C 08 R i k$ & NM_023516 & 26.24 & 43.88 & 23.96 & 7.95 & Unknown \\
\hline Fabp4 & NM_024406 & 21.14 & 34.34 & 33.42 & 40.57 & Fatty acid binding protein 4 \\
\hline$M t 1$ & NM_013602 & 20.97 & 38.58 & 38.89 & 11.35 & Metallothionein 1 \\
\hline Saa3 & NM_011315 & 20.69 & 41.23 & 46.75 & 42.08 & Serum amyloid A3 \\
\hline Rab30 & NM_029494 & 20.05 & 52.09 & 6.48 & $<3.00$ & Member of the RAS oncogene family \\
\hline
\end{tabular}

(Genetyx, Tokyo, Japan) (Tables I and II). To confirm whether the fragments amplified in the qPCR were derived from the target sequences, the qPCR-amplified fragments were puri- fied though $2 \%$ agarose gel electrophoresis and subjected to direct sequence analysis using the ABI PRISM 3100 Genetic Analyzer (Applied Biosystems). 
Histological study. Tissue sections on glass-slides were stained with hematoxylin and eosin (H\&E) and photographed through a MIRAX desk (Carl Zeiss, Tokyo, Japan).

In situ hybridization. In situ hybridization was performed as described earlier (11), with the following exception: the hybridization was carried out in a solution containing $50 \%$ formamide, $2 \mathrm{X} \mathrm{SSC}, 1.0 \mathrm{mg} / \mathrm{ml}$ transfer RNA, $1.0 \mathrm{mg} / \mathrm{ml}$ salmon sperm DNA, $1.0 \mathrm{mg} / \mathrm{ml}$ BSA, $1.0 \mathrm{mg} / \mathrm{ml}$ yeast RNA, $2.0 \% \mathrm{SDS}$, and $3.0 \mu \mathrm{g} / \mathrm{ml}$ digoxigenin (DIG)-labeled cRNA probe at $42^{\circ} \mathrm{C}$ for $60 \mathrm{~h}$. Hybridization signals were detected with the NBT/BCIP system (Roche Diagnostics, Tokyo, Japan), and photographed through the MIRAX desk (Carl Zeiss) under the same conditions to perform the comparison of signal intensities.

For the cRNA probes, regions corresponding to those examined by qPCR were selected to make ca.120 nucleotidesequences (Table II). As a negative control cRNA probe, a LNE cRNA probe that did not give a signal in any of the tissues was used for in situ hybridization (12). In addition, a mouse Prml antisense cRNA probe was used as a positive control by detecting Prml mRNA in $8 \mathrm{~W}$ testis sections for all the in situ hybridization experiments. These DIG-labeled cRNA probes were obtained from Tsukuba GeneTech Laboratories (Ibaraki, Japan).

\section{Results}

Identification of novel genes participating in liver regeneration. Cytokines including TNF $\alpha$ and IL- 6 have been demonstrated to play key roles in the priming phase $(0-4 \mathrm{~h}$ post $\mathrm{PH}$ ) of liver regeneration. In the present study, we screened up-regulated genes during liver regeneration at the early phase (until $6 \mathrm{~h}$ post $\mathrm{PH}$ ) using microarray analysis in order to obtain novel genes involved in liver regeneration. The microarray analysis revealed that the expression of 71 genes was elevated more than 3 -fold at 2 and $6 \mathrm{~h}$ post $\mathrm{PH}$, as compared to $0 \mathrm{~h}$ (data not shown). The top 10 overexpressed genes are listed in Table III. Mt2, Igfbpl, Saal, Saa 2 and $M t 1$, listed in Table III, were reported as up-regulated genes during the priming phase of liver regeneration in earlier studies (13-15). In addition, a 5.6-fold elevation of Ccnd1, which is involved in DNA replication, was observed at $24 \mathrm{~h}$ post PH (data not shown). This result was also consistent with the findings obtained in earlier studies (16-18). Furthermore, $H \& E$ staining revealed that hepatocytes followed the process of liver regeneration with the passage of time after PH (data not shown). These histological observations indicated that the liver regeneration post $\mathrm{PH}$ in the present study followed the same process as reported in earlier studies.

Based on these findings, Rab30 and S100a9 were selected for precise analysis as candidates of novel genes to be involved in the initiation of liver regeneration, though $S 100 a 9$ had been listed as an up-regulated gene in the SAGE (serial analysis of gene expression) analysis (18). In view of the fact that S100a9 was shown to form a heterodimer with S100a8 in neutrophils and monocytes (19-21), it is possible that $5100 a 8$ is also up-regulated together with S100a9. However, S100a8 data were eliminated in the Feature Extraction process because at least one value at the time-points showed no significant differ-
Table IV. Expression of Rab family genes in liver regeneration using microarray analysis.

\begin{tabular}{|c|c|c|c|c|c|}
\hline \multirow[b]{2}{*}{ Gene symbol } & \multirow[b]{2}{*}{ Accession no. } & \multicolumn{4}{|c|}{ Expression fold } \\
\hline & & $2 \mathrm{~h}$ & $6 \mathrm{~h}$ & $12 \mathrm{~h}$ & $24 \mathrm{~h}$ \\
\hline$R a b 1$ & NM_008996 & 1.24 & 1.75 & 2.01 & 1.71 \\
\hline$R a b 1 b$ & NM_029576 & 0.62 & 0.54 & 0.63 & 0.63 \\
\hline$R a b 2$ & NM_021518 & 1.00 & 1.07 & 1.32 & 1.32 \\
\hline$R a b 2 b$ & NM_172601 & 0.90 & 1.05 & 1.14 & 0.83 \\
\hline$R a b 3 a$ & NM_009001 & 0.36 & 0.15 & 0.33 & 0.47 \\
\hline${ }^{\mathrm{a}} R a b 3 b$ & NM_023537 & 0.99 & 0.94 & 0.91 & 0.84 \\
\hline $\operatorname{Rab3d}$ & NM_031874 & 0.60 & 0.32 & 0.41 & 1.14 \\
\hline$R a b 4 a$ & NM_009003 & 1.04 & 0.77 & 1.21 & 1.49 \\
\hline$R a b 4 b$ & NM_029391 & 1.14 & 1.56 & 1.63 & 1.03 \\
\hline Rab5a & NM_025887 & 1.19 & 1.48 & 1.25 & 1.02 \\
\hline${ }^{\mathrm{a}} R a b 5 b$ & NM_011229 & 0.58 & 0.89 & 1.07 & 0.86 \\
\hline$R a b 5 c$ & NM_024456 & 1.83 & 1.95 & 1.35 & 1.70 \\
\hline Rab6 & NM_024287 & 0.99 & 1.32 & 1.75 & 1.25 \\
\hline${ }^{\mathrm{a}} R a b 6 b$ & NM_173781 & 0.98 & 0.93 & 0.90 & 0.82 \\
\hline $\operatorname{Rab7}$ & NM_009005 & 1.11 & 1.34 & 1.36 & 1.15 \\
\hline$R a b 8 a$ & NM_023126 & 0.72 & 0.71 & 0.86 & 1.12 \\
\hline${ }^{\mathrm{a}} R a b 8 b$ & NM_173413 & 1.01 & 1.26 & 2.79 & 4.19 \\
\hline Rab9 & NM_019773 & 1.17 & 2.00 & 1.25 & 1.56 \\
\hline${ }^{\mathrm{a}} R a b 9 b$ & NM_176971 & 1.00 & 0.96 & 0.73 & 0.98 \\
\hline Rab10 & NM_016676 & 0.89 & 0.95 & 0.80 & 0.78 \\
\hline Rabl1a & NM_017382 & 0.94 & 1.01 & 1.04 & 1.53 \\
\hline$R a b 11 b$ & NM_008997 & 0.94 & 0.96 & 1.33 & 0.64 \\
\hline Rab12 & NM_024448 & 1.39 & 2.25 & 1.20 & 1.48 \\
\hline$R a b 13$ & NM_026677 & 1.16 & 0.83 & 0.91 & 2.32 \\
\hline Rab14 & NM_026697 & 1.03 & 0.93 & 0.98 & 0.85 \\
\hline à $R a b 15$ & NM_134050 & 1.83 & 8.06 & 1.28 & 8.19 \\
\hline Rab17 & NM_008998 & 0.71 & 0.65 & 0.54 & 0.98 \\
\hline Rabl8 & NM_181070 & 1.67 & 2.79 & 2.34 & 1.89 \\
\hline${ }^{\mathrm{a}} \mathrm{Rab19}$ & NM_011226 & 1.28 & 1.28 & 0.87 & 1.44 \\
\hline Rab20 & NM_011227 & 1.68 & 1.15 & 0.85 & 0.63 \\
\hline$R a b 21$ & NM_024454 & 1.13 & 1.08 & 1.07 & 1.21 \\
\hline$R a b 22 a$ & NM_024436 & 0.71 & 0.94 & 0.60 & 0.61 \\
\hline$R a b 23$ & NM_008999 & 0.45 & 0.88 & 1.81 & 1.64 \\
\hline Rab24 & NM_009000 & 0.93 & 0.74 & 0.93 & 0.80 \\
\hline${ }^{\mathrm{a}} \mathrm{Rab25}$ & NM_016899 & 1.48 & 1.15 & 0.92 & 1.21 \\
\hline${ }^{\mathrm{a}} \mathrm{R} a b 26$ & AK080607 & 0.99 & 0.94 & 0.90 & 1.05 \\
\hline${ }^{\mathrm{a}} R a b 27 a$ & NM_023635 & 1.01 & 0.62 & 0.94 & 1.43 \\
\hline${ }^{\mathrm{a}} R a b 27 b$ & AK161136 & 0.97 & 0.92 & 0.88 & 0.82 \\
\hline Rab28 & NM_027295 & 1.42 & 1.66 & 1.78 & 2.24 \\
\hline Rab30 & NM_029494 & 20.05 & 52.09 & 6.48 & 1.42 \\
\hline Rab31 & NM_133685 & 2.31 & 3.45 & 2.59 & 4.17 \\
\hline Rab32 & NM_026405 & 0.59 & 0.54 & 0.59 & 1.36 \\
\hline Rab33a & NM_011228 & 0.97 & 0.86 & 1.11 & 1.15 \\
\hline Rab33b & NM_016858 & 0.90 & 2.18 & 2.03 & 1.13 \\
\hline Rab34 & NM_033475 & 1.15 & 0.80 & 1.22 & 1.53 \\
\hline Rab35 & NM_198163 & 0.80 & 1.18 & 1.53 & 1.15 \\
\hline${ }^{\mathrm{a}} \mathrm{Rab36}$ & NM_029781 & 1.00 & 0.95 & 0.93 & 0.87 \\
\hline${ }^{\mathrm{a}} \mathrm{R} a b 37$ & NM_021411 & 1.00 & 1.29 & 0.91 & 0.85 \\
\hline${ }^{\mathrm{a}} \mathrm{Rab38}$ & NM_028238 & 0.98 & 0.94 & 1.68 & 1.41 \\
\hline${ }^{\mathrm{a} R a b 39}$ & NM_175562 & 0.66 & 0.78 & 3.29 & 2.44 \\
\hline${ }^{\mathrm{a}} R a b 39 b$ & NM_175122 & 1.17 & 0.92 & 1.26 & 1.87 \\
\hline${ }^{\mathrm{a}} \mathrm{Rab} 40 \mathrm{~b}$ & NM_139147 & 0.99 & 0.95 & 0.91 & 0.85 \\
\hline$R a b 40 c$ & NM_139154 & 0.55 & 0.66 & 1.00 & 0.72 \\
\hline
\end{tabular}

aData were not found in the processed data, but existed in the row data. They were eliminated in the process of the row data with the Feature Extraction due to fact that at least one value at the time points did not show significant difference between the values and the background. 
Table V. Expression of S100 family genes in liver regeneration using microarray analysis.

\begin{tabular}{|c|c|c|c|c|c|}
\hline \multirow[b]{2}{*}{ Gene symbol } & \multirow[b]{2}{*}{ Accession no. } & \multicolumn{4}{|c|}{ Expression fold } \\
\hline & & $2 \mathrm{~h}$ & $6 \mathrm{~h}$ & $12 \mathrm{~h}$ & $24 \mathrm{~h}$ \\
\hline S100al & NM_011309 & 1.45 & 1.62 & 1.01 & 1.20 \\
\hline${ }^{\mathrm{a}} \mathrm{S} 100 \mathrm{a3}$ & NM_011310 & 0.69 & 1.44 & 1.30 & 1.35 \\
\hline S100a4 & NM_011311 & 3.82 & 9.38 & 2.39 & 19.72 \\
\hline${ }^{\mathrm{a}} \mathrm{S} 100 \mathrm{a} 5$ & NM_011312 & 1.00 & 0.86 & 0.89 & 0.81 \\
\hline S100a6 & NM_011313 & 3.46 & 5.44 & 2.20 & 11.27 \\
\hline${ }^{\mathrm{a}} \mathrm{S} 100 \mathrm{a} 8$ & NM_013650 & 60.14 & 116.69 & 38.96 & 80.17 \\
\hline S100a9 & NM_009114 & 48.55 & 38.74 & 16.98 & 23.18 \\
\hline S100alo & NM_009112 & 2.87 & 6.30 & 7.68 & 13.77 \\
\hline S100all & NM_016740 & 2.87 & 4.17 & 5.55 & 7.47 \\
\hline S100a13 & NM_009113 & 1.29 & 1.31 & 0.76 & 1.29 \\
\hline${ }^{\mathrm{a} S} 100 \mathrm{a} 14$ & NM_025393 & 0.69 & 2.82 & 0.36 & 4.27 \\
\hline${ }^{\mathrm{a} S 100 a 15}$ & NM_199422 & 1.01 & 0.95 & 0.98 & 0.86 \\
\hline S100a16 & NM_026416 & 0.84 & 0.87 & 1.12 & 1.96 \\
\hline${ }^{\mathrm{a} S 100 b}$ & NM_009115 & 1.74 & 1.32 & 0.91 & 1.18 \\
\hline${ }^{\mathrm{a}} \mathrm{S} 100 \mathrm{~g}$ & NM_009789 & 1.00 & 94.79 & 0.92 & 0.86 \\
\hline
\end{tabular}

aData were not found in the processed data, but existed in the row data. They were eliminated in the process of the row data with the Feature Extraction due to fact that at least one value at the time-points did not show significant difference between the values and the background.

ence from the background value in the microarray analysis. Therefore, the $R a b$ and $S 100$ family members including $S 100 a 8$ eliminated in the Feature Extraction process were re-examined (Tables IV and V). As shown in Table V, S100a8 was up-regulated in the eliminated family members and its up-regulation pattern was similar to that of S100a9. Consequently, Rab30, S100a8, and S100a9 were the only members up-regulated in the gene families examined, and it was indicated that Rab30 and S100a8/S100a9 had unique functions among the respective family members, and S100a9 functioned together with $S 100 a 8$ in liver regeneration.
In order to confirm the up-regulation of Rab30, S100a8, and $S 100 a 9$ at $2 \mathrm{~h}$ and $6 \mathrm{~h}$ post PH, RT-qPCR was performed independently for all the total RNA samples ( $\mathrm{n}=3$ at each timepoint). In addition, the expression levels of Igfbpl and Ccndl were examined as authentic controls in liver regeneration. The expression of these genes was normalized based on the value of EGFP RNA (22) and were calculated to obtain means $\pm \mathrm{SE}$ at each time-point. The expression of Igfbpl showed a significant 44.3-fold increase at $2 \mathrm{~h}$ post $\mathrm{PH}$ as compared to that at $0 \mathrm{~h}$, and gradually decreased to 7.1-fold; and that of Ccndl was elevated 3.1-fold at $24 \mathrm{~h}$ post $\mathrm{PH}$ as compared to that of $0 \mathrm{~h}$ (data not shown). These results were essentially consistent with those of the microarray analysis and with those reported by others $(13,16-18)$. In the case of Rab30, the highest expression, a 26.4-fold increase over the expression at $0 \mathrm{~h}$ post $\mathrm{PH}$, was observed at $2 \mathrm{~h}$ post $\mathrm{PH}$ and decreased gradually in the following time-points examined (Fig. 1A). The expression of S100a9 showed a 37.9-fold increase at $2 \mathrm{~h}$ post $\mathrm{PH}$, gradually decreased until $12 \mathrm{~h}$ post $\mathrm{PH}$ to 14.6-fold, and increased to 30.0 -fold at 24 h post PH (Fig. 1B). For S100a8, its expression was elevated 71.8 -fold at $6 \mathrm{~h}$ post $\mathrm{PH}$, decreased to 26.9-fold at $12 \mathrm{~h}$ post $\mathrm{PH}$, and increased again to 120.0 -fold at $24 \mathrm{~h}$ post $\mathrm{PH}$, following a similar pattern with that of the S100a9 expression (Fig. 1). These findings were essentially consistent with those obtained from the microarray analysis.

In the RT-qPCR, total liver RNAs prepared from the sham-operated mice at each time-point were studied for the expression levels of the genes, in order to examine whether the elevated expression levels of the genes were the result of $\mathrm{PH}$. As shown in Fig. 1, it has been revealed that all or a major part of the elevated expression levels of Rab30, S100a8 and S100a9 were attributed to PH. These results, taken together, indicate that $R a b 30$ plays a role in the priming phase of liver regeneration, and that $S 100 a 8 / S 100 a 9$ play a role in the priming and in a later phase starting from $24 \mathrm{~h}$ post $\mathrm{PH}$. These results also indicate that $R a b 30$ and $5100 a 8 / S 100 a 9$ have different functions in liver regeneration.

Rab30 and S100a8/S100a9 expression in other organs of mice at 6 host $\mathrm{PH}$, and in livers at various developmental stages. To obtain information about the functions of Rab30
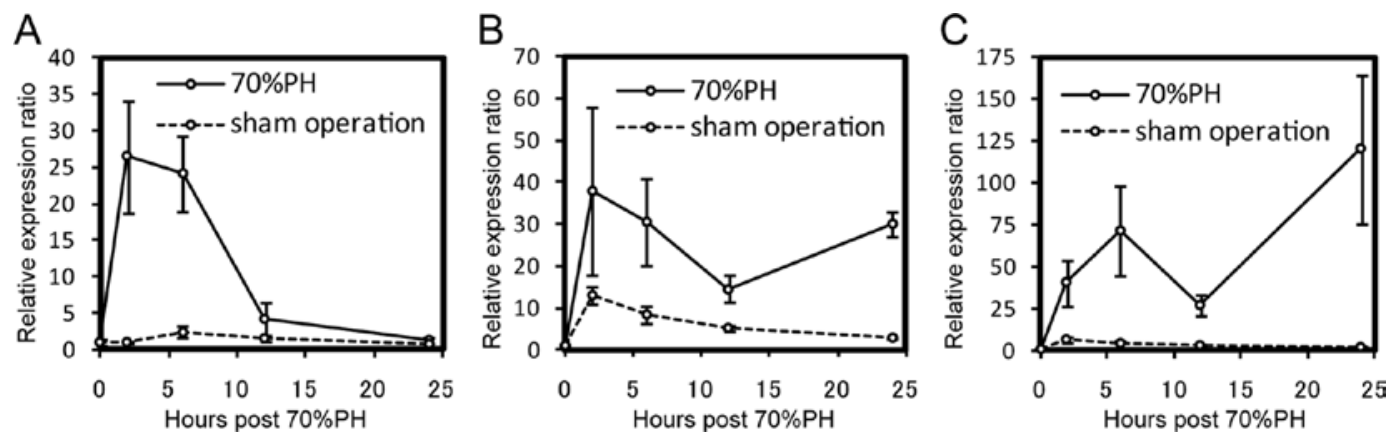

Figure 1. Relative amount of (A) Rab30, (B) S100a9 and (C) S100a8 mRNAs in the early phase of liver regeneration. Total RNAs were isolated from regenerating livers of PH mice, and from livers of sham-operated mice ( $\mathrm{n}=3$ at $0,2,6,12$, and $24 \mathrm{~h}$ post PH or sham-operation), and cDNAs from these total RNAs were synthesized as described in Materials and methods. The amounts of Rab30, S100a9 and S100a8 mRNAs in the total RNA samples were determined as described in Materials and Methods by RT-qPCR using the primer pairs listed in Table I. Means \pm SE were obtained using the standard-curve method according to the procedure recommended by Applied Biosystems, and calculated taking the values of qPCR at $0 \mathrm{~h}$ post PH (normal livers) as 1.0 . Solid lines represent the relative mRNA amounts of respective genes in the regenerating livers. Dashed lines represent the relative mRNA amounts of respective genes in the livers of sham-operated mice. The ordinates represent relative mRNA amounts and the abscissas the periods of time in hours post PH or sham-operation. 
A

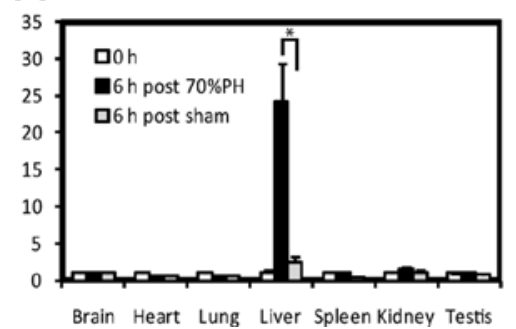

B

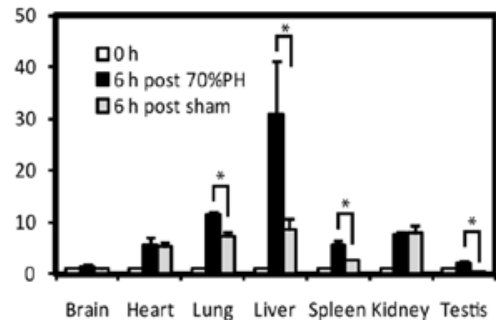

C

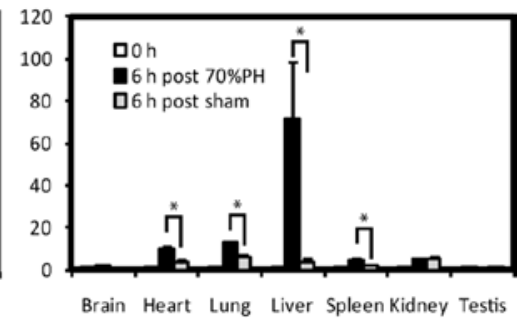

Figure 2. Expression of (A) Rab30, (B) S100a9 and (C) S100a8 mRNA in various organs at 6 h post PH. The relative expression of Rab30, S100a9 and S100a 8 mRNA in the brain, heart, lung, liver, spleen, kidney, and testis at $6 \mathrm{~h}$ post PH were determined by RT-qPCR using the primer pairs listed in Table I Means $\pm \mathrm{SE}$ of the organs/tissues were obtained using a standard curve method, and calculated taking the values of qPCR for corresponding normal organs/ tissues as 1.0. The ordinate represents relative mRNA amounts.

A

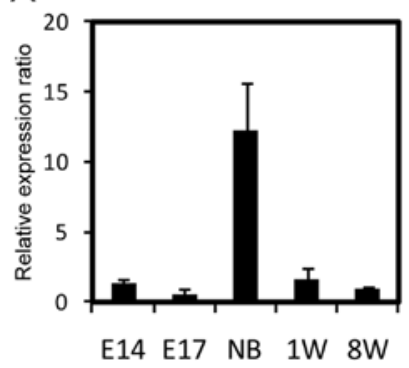

B

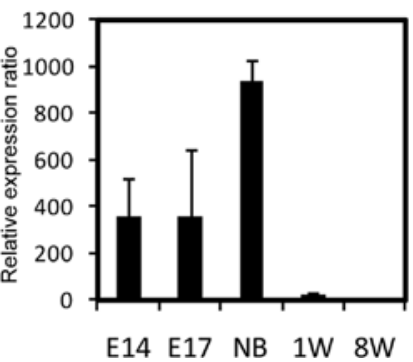

C

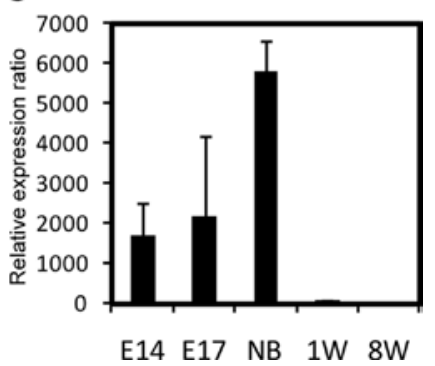

Figure 3. Expression of (A) Rab30, (B) $S 100 a 9$ and (C) $S 100 a 8$ mRNA in livers at various developmental stages. The relative expression levels of Rab30, S100a 9 and S100a 8 mRNA in livers of E14, E17, NB, 1W, and 8W mice were determined by RT-qPCR as described in Materials and methods. Means \pm SE in the livers at various developmental stages were calculated taking the mean values of $8 \mathrm{~W}$ as 1.0 .
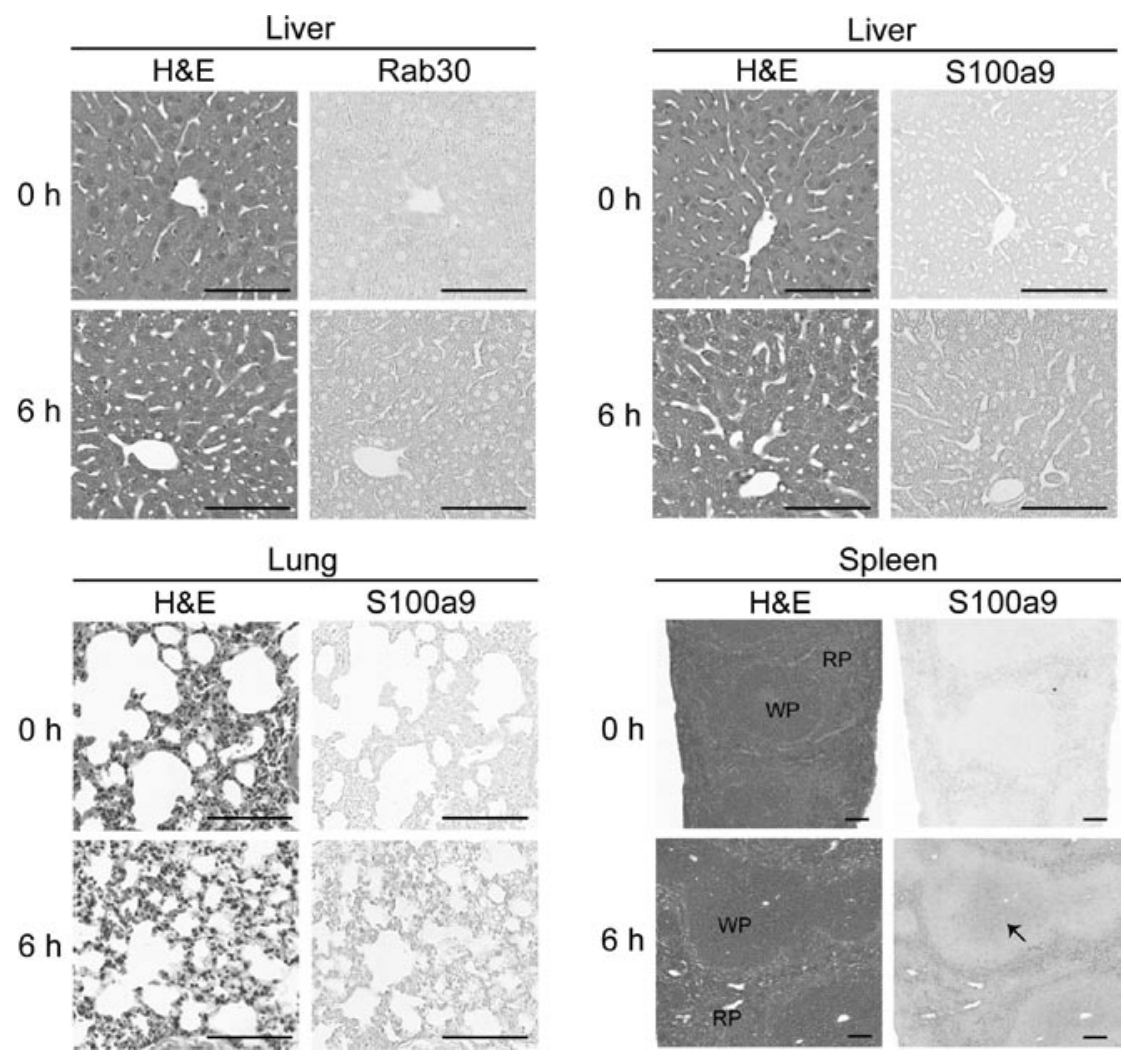

Figure 4. Localization of Rab30 and S100a9 mRNA in organs at $6 \mathrm{~h}$ post PH. At $6 \mathrm{~h}$ post PH significant up-regulation of Rab30 as compared to that of sham-operated mice was observed in lvers subjected to in situ hybridization. Likewise, significant up-regulation of S100a9 is observed in the liver, lung, and spleen at $6 \mathrm{~h}$ post PH as determined by in situ hybridization. In situ hybridization was performed using DIG-labeled Rab30 or S100a9 antisense cRNA probes, according to the procedure described in Materials and methods. The cRNA probe sequences are indicated in Table II. Serial sections were subjected to H\&E staining and in situ hybridization, followed by photographing of the corresponding regions. RP, red pulp; WP, white pulp. Scale bar, $100 \mu \mathrm{m}$. 


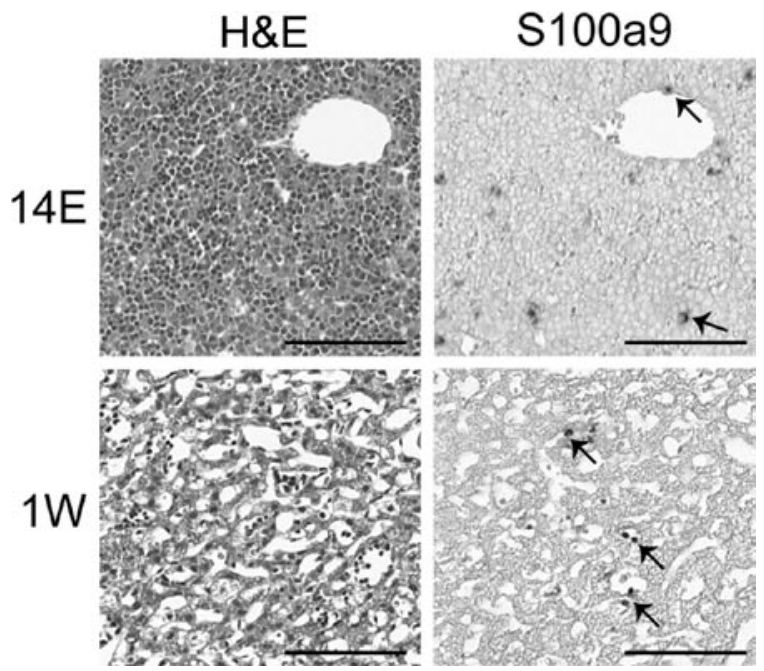

Figure 5. Localization of S100a9 mRNA in livers at various developmental stages. Localization of S100a9 mRNA in livers at the developmental stages was detected by in situ hybridization using the DIG-labeled cRNA probe as described in Table II. Serial sections of the liver at each stage were used for H\&E staining, and the detection of S100a9 mRNAs. Arrows indicate nonparenchymal cells expressing $S 100 a 9$ mRNA. 14E, embryonic day 14; $1 \mathrm{~W}$, one-week-old. Scale bar, $100 \mu \mathrm{m}$.

and S100a8/S100a9, the expression levels of Rab30, S100a8, and $S 100 a 9$ were measured in the brain, heart, lung, spleen, kidney and testis of mice at $6 \mathrm{~h}$ post $\mathrm{PH}$ in comparison with those of sham-operated and normal mice. As shown in Fig. 2, Rab30 demonstrated no significant difference between $\mathrm{PH}$ mice and sham-operated/normal mice, whereas S100a8 and S100a9 showed significant differences in their expression in organs other than the liver between $\mathrm{PH}$ mice and shamoperated/normal mice. The fact that Rab30 expression was elevated only in liver led us to speculate that the signal for Rab30 activation was conveyed directly to hepatocytes after PH. As for S100a8 and S100a9, since their elevated expression levels were observed in the liver as well as in other organs, the signal for S100a8 and S100a9 activation was inferred to be hematogenously conveyed to hepatocytes.

We further examined the expression levels of Rab30 and $S 100 a 8 / S 100 a 9$ in the process of liver formation and maintenance using the livers of mice at E14, E17, NB, 1W and 8W. Rab30 showed a marked expression only in NB livers, whereas $\$ 100 a 8$ and $\$ 100 a 9$ showed relatively higher expression in embryonic livers, the highest in NB livers like Rab30, and very low expression levels in $1 \mathrm{~W}$ and $8 \mathrm{~W}$ livers (Fig. 3). These observations indicate that in addition to the involvement in liver regeneration, Rab30 may be involved in the functional switch from hematopoietic support to metabolic homeostasis; and $S 100 a 8 / S 100 a 9$ may be involved in hematopoietic support as well as in the functional switch.

Expression sites of Rab30 and S100a9 in the organs of mice at $6 \mathrm{~h}$ post $\mathrm{PH}$ and in livers at various developmental stages. For analysis of the gene expression sites in organs, in situ hybridization was performed using DIG-labeled cRNA probes as described in Materials and methods. Due to the fact that the expression profiles of S100a8 and S100a9 were essentially the same (see above) and the fact that S100a8 and
Sl00a9 form a heterodimer to function in cells (19-21), the S100a9 DIG-labeled cRNA probe was used as a representative probe for $S 100 a 8 / S 100 a 9$ analysis. The organs at $6 \mathrm{~h}$ post PH showing significant elevation of Rab30 and S100a8/ S100a9 (the liver for Rab30, and the liver, lung, and spleen for S100a9) were subjected to in situ hybridization. Rab30 and S100a9 mRNAs were uniformly detected in hepatocytes (Fig. 4). In addition, S100a9 mRNA was detected uniformly in alveolar cells in lung and in the central region of white pulp populated with B and T cells and in red pulp populated with monocytes and macrophages (23) in the spleen (Fig. 4).

When the liver was examined at various developmental stages, E14, E17, NB, 1W and 8W, Rab30 expression was observed to be uniform in fetal and postnatal hepatocytes (data not shown), and S100a9 expression was observed to be more specific in a portion of non-parenchymal cells, possibly in myeloid cells (23) in E14 and 1W livers (Fig. 5), and more uniform in E17 and NB livers (data not shown).

\section{Discussion}

In order to understand the liver regeneration process post $\mathrm{PH}$, numerous studies have been conducted since Higgins et al first described the liver regeneration of rodents that underwent a two-third removal of the liver in 1931 (3). Recently, a number of genes have been shown to participate in the initiation of liver regeneration $(1,7,8)$. In the present study, Rab30 and $S 100 a 8 / S 100 a 9$ genes have been newly identified to be up-regulated at 2 and $6 \mathrm{~h}$ post $\mathrm{PH}$ using microarray analysis and RT-qPCR. The Rab30 and S100a8/S100a9 expression amounts and sites were investigated in various organs of the mice at $6 \mathrm{~h}$ post $\mathrm{PH}$ and in the livers at various developmental stages. According to our results, Rab30 and S100a8/S100a9 were shown to participate in the initiation of liver regeneration in possibly different ways. In addition, Rab30 appeared be involved mainly in the functional switch from hematopoietic support to metabolic homeostasis; and S100a8/S100a9, in the hematopoietic support as well as in the functional switch.

$R a b 30$ is a member of the $R a b$ family belonging to the Ras superfamily, which is found in species ranging from yeast to human and encode the proteins having GTPase activity. Rab family members are shown to function as regulators of particular steps in membrane trafficking pathways (24). S100a8 and $S 100 a 9$ are members of the $S 100$ family encoding the proteins bearing a $\mathrm{Ca}^{2+}$ binding EF-hand motif. S100a8 and S100a9 have been shown to form a heterodimer in neutrophils and monocytes, and was detected extracellulary on the vasculature at inflammatory sites, indicating that $5100 \mathrm{a} 8 / \mathrm{S} 100 \mathrm{a} 9$ may influence neutrophil chemotaxis and adhesion (19-21).

In order to examine the possible similarity of the signal transduction pathway of Rab30 with the pathways of $\mathrm{Hgf}$, Tnfa, Tnfrsfla (Tnfrl), Il6, Tgfa, Egf, Egfr, Met, Igfbpl, Tgfbl, Tgfbrl, Mmp9, which had been demonstrated to be up-regulated during the priming phase of liver regeneration in earlier studies $(1,7,8)$, the $2 \mathrm{~kb}$ upstream regions of Rab30 were compared with those of the above-mentioned genes. The Rab30 upstream region was shown to have no notable similarity with that of any other genes examined. To the best of our knowledge, the role of Rab30 has been studied in Drosophila using microarray analysis and an RNA interference system 
(25). It was demonstrated that Rab30 is involved in dorsal closure in embryogenesis. The amino acid sequence of mouse Rab30 is 63\% identical to that of Drosophila Rab30, and $100 \%$ identical to that of humans and dogs (25). These findings indicate that $R a b 30$ is also involved in the early stages of development in mammals, including mice, in addition to its involvement in liver regeneration and the functional switch in NB from hematopoiesis to metabolic homeostasis.

When the upstream regions of S100a8 and S100a9 were examined, no responsive elements were found in $S 100 a 8$; and the NF- $\mathrm{BB}$ and TATA box were found, in S100a9. Since no significant similarity was found between the two regions, it was indicated that S100a8 and S100a9 might be differently controlled. However, based on the fact that S100a8 and S100a9 have been found to form a heterodimer in neutrophils and monocytes, and have been detected extracellulary on the vasculature at inflammatory sites (19-21), in addition to the fact that administration of the immunosuppressant FK778 impaired liver regeneration in $\mathrm{PH}$ rats (26), the heterodimer of $\mathrm{S} 100 \mathrm{a} 8$ and $\mathrm{S} 100 \mathrm{a} 9$ has been inferred to play a role in the inflammatory process of the priming phase in the liver regeneration.

The present study indentified Rab30 and S100a8/S100a9 as novel genes, which were shown to participate in the initiation of liver regeneration. The genes were indicated to be under different signal transduction pathways and might play different roles in liver regeneration as well as in liver formation. Future studies including the investigation of knock-out mice of these genes will provide additional information to understand their impact on liver regeneration.

\section{Acknowledgements}

We are grateful to Dr Yoshiaki Nagamura and Ms. Ritsuko Motoyama, National Institute of Agrobiological Sciences, Tsukuba, for excellent support in the mirroarray analysis. The present study has been supported in part by Grants-in-Aid from the Ministry of Education, Culture, Sports, Science, and Technology of Japan (MEXT).

\section{References}

1. Taub R: Liver regeneration: from myth to mechanism. Nat Rev Mol Cell Biol 5: 836-847, 2004.

2. Hata S, Namae M and Nishina H: Liver development and regeneration: from laboratory study to clinical therapy. Dev Growth Differ 49: 163-170, 2007.

3. Higgins GM and Anderson RM: Experimental pathology of the liver. Arch Pathol 12: 186-202, 1931.

4. Cressman DE, Greenbaum LE, DeAngelis RA, Ciliberto G, Furth EE, Poli V and Taub R: Liver failure and defective hepatocyte regeneration in interleukin-6-deficient mice. Science 274: 1379-1383, 1996.

5. Fujita J, Marino MW, Wada H, Jungbluth AA, Mackrell PJ, Rivadeneira DE, Stapleton PP and Daly JM: Effect of TNF gene depletion on liver regeneration after partial hepatectomy in mice. Surgery 129: 48-54, 2001.

6. Michalopoulos GK and DeFrances MC: Liver regeneration. Science 276: 60-66, 1997.
7. Michalopoulos GK: Liver regeneration. J Cell Physiol 213: 286-300, 2007.

8. Fausto N, Campbell JS and Riehle KJ: Liver regeneration. Hepatology 43: S45-S53, 2006.

9. Kiuchi S, Yamada T, Kiyokawa N, Saito T, Fujimoto J and Yasue $\mathrm{H}$ : Genomic structure of swine taste receptor family 1 member 3, TAS1R3, and its expression in tissues. Cytogenet Genome Res 115: 51-61, 2006.

10. Clark TA, Schweitzer AC, Chen TX, Staples MK, Lu G, Wang H, Williams A and Blume JE: Discovery of tissue-specific exons using comprehensive human exon microarrays. Genome Biol 8: R64, 2007.

11. Ohtsuki T, Furuya S, Yamada T, Nomura S, Hata J, Yabe Y and Hosoda Y: Gene expression of noncollagenous bone matrix proteins in the limb joints and intervertebral disks of the twy mouse. Calcif Tissue Int 63: 167-172, 1998.

12. Chiba M, Kubo M, Miura T, Sato T, Rezaeian AH, Kiypsawa H, Ohkohchi N and Yasue H: Localization of sense and antisense transcripts of $\operatorname{Prdx} 2$ gene in mouse tissues. Cytogenet Genome Res 121: 222-231, 2008.

13. White P, Brestelli JE, Kaestner KH and Greenbaum LE: Identification of transcriptional networks during liver regeneration. J Biol Chem 280: 3715-3722, 2005.

14. Ho CM, Lee PH, Lai YT, Hu RH, Ho MC and Wu YM: Gene expression profiles in living donors immediately after partial hepatectomy - the initial response of liver regeneration. J Formos Med Assoc 106: 288-294, 2007.

15. Xu W, Wang S, Wang G, Wei H, He F and Yang X: Identification and characterization of differentially expressed genes in the early response phase during liver regeneration. Biochem Biophys Res Commun 278: 318-325, 2000.

16. Togo S, Makino H, Kobayashi T, Morita T, Shimizu T, Kubota T, Ichikawa Y, Ishikawa T, Okazaki Y, Hayashizaki Y and Shimada $\mathrm{H}$ : Mechanism of liver regeneration after partial hepatectomy using mouse cDNA microarray. J Hepatol 40: 464-471, 2004.

17. Kumamoto T, Togo S, Ishibe A, Morioka D, Watanabe K, Takahashi T, Shimizu T, Matsuo K, Kubota T, Tanaka K, Nagashima Y, Kawai J, Hayashizaki Y and Shimada H: Role of nitric oxide synthesized by nitric oxide synthase 2 in liver regeneration. Liver Int 28: 865-877, 2008.

18. Cimica V, Batusic D, Haralanova-Ilieva B, Chen Y, Hollemann T, Pieler T and Ramadori G: Serial analysis of gene expression (SAGE) in rat liver regeneration. Biochem Biophys Res Commun 360: 545-552, 2007.

19. Donato R: S100: a multigenic family of calcium-modulated proteins of the EF-hand type with intracellular and extracellular functional roles. Int J Biochem Cell Biol 33: 637-668, 2001.

20. Striz I and Trebichavsky I: Calprotectin - a pleiotropic molecule in acute and chronic inflammation. Physiol Res 53: 245-253, 2004.

21. Ryckman C, Vandal K, Rouleau P, Talbot M and Tessier PA: Proinflammatory activities of S100: proteins S100A8, S100A9, and S100A8/A9 induce neutrophil chemotaxis and adhesion. J Immunol 170: 3233-3242, 2003.

22. Rezaeian AH, Isokane T, Nishibori M, Chiba M, Hiraiwa N, Yashizawa $M$ and Yasue H: $\alpha$ CGRP and $\beta$ CGRP transcript amount in mouse tissues of various developmental stages and their tissue expression sites. Brain Dev 31: 682-693, 2009.

23. Lagasse E and Weissman IL: Mouse MRP8 and MRP14, two intracellular calcium-binding proteins associated with the development of the myeloid lineage. Blood 79: 1907-1915, 1992.

24. Stenmark $h$ and Olkkonen VM: The Rab GTPase family. Genome Biol 2: Reviews3007, 2001.

25. Thomas C, Rousset R and Noselli S: JNK signalling influences intracellular trafficking during Drosophila morphogenesis through regulation of the novel target gene Rab30. Dev Biol 331: 250-260, 2009.

26. Biglarnia AR, Lorant T, Lee HS, Tufveson G, Totsch $M$ and Malago M: Liver regeneration is impaired by FK778 in partially hepatectomized rats, while supplemental uridine restores both liver growth and hepatocyte proliferation. Hepatol Res 39: 86-92, 2009. 